See Article page $\mathrm{XXX}$.

\section{Commentary: Aortic root replacement in the reoperative setting}

\author{
Megan Schultz, MD, MS, and Ming-Sing Si, MD
}

Aortic root replacement (ARR) is performed for a variety of indications, including aneurysm, infection, dissection, and degeneration of a previous conduit. The operation is considered safe, with overall operative mortality reported to be approximately $5 \%$ in a recent national series. ${ }^{1}$ With an aging population, patients may require ARR after a previous cardiac operation or may require redo ARR to address a degenerated or infected original repair. While multiple recent series demonstrate the safety of a redo ARR, ${ }^{2,3}$ few have drawn a comparison between first-time and redo ARR. ${ }^{4}$ Furthermore, data directly comparing first-time ARR with redo ARR, both in the setting of a redo sternotomy, are lacking.

In this issue, Brown and colleagues ${ }^{5}$ present a retrospective analysis of aortic root operations at a single institution. Included in the analysis were patients who underwent complete ARR for any indication-other aortic root operations such as valve-sparing root replacement were excluded. The authors have achieved an excellent follow-up rate at $98.4 \%$; midterm follow-up data are presented. The goals of their study are 2-fold. First, the authors compare patients undergoing ARR via first-time sternotomy $(n=595)$ and patients undergoing ARR via redo sternotomy, regardless of the indication for the original operation $(n=298)$. Propensity matching was performed, resulting in 220

\footnotetext{
From the Division of Cardiac Surgery, Department of Surgery, David Geffen School of Medicine at UCLA, Los Angeles, Calif.

Disclosures: The authors reported no conflicts of interest.

The Journal policy requires editors and reviewers to disclose conflicts of interest and to decline handling or reviewing manuscripts for which they may have a conflict of interest. The editors and reviewers of this article have no conflicts of interest.

Received for publication Oct 18, 2021; revisions received Oct 18, 2021; accepted for publication Oct 20, 2021.

Address for reprints: Ming-Sing Si, MD, Division of Cardiac Surgery, Department of Surgery, David Geffen School of Medicine, UCLA Division of Cardiac Surgery, 62-246 CHS, 10833 Le Conte Ave, Los Angeles, CA 90095-1741 (E-mail: msi@mednet.ucla.edu).

J Thorac Cardiovasc Surg 2021; $\mathbf{\square}: 1-2$

$0022-5223 / \$ 36.00$

Copyright (C) 2021 by The American Association for Thoracic Surgery

https://doi.org/10.1016/j.jtcvs.2021.10.030
}

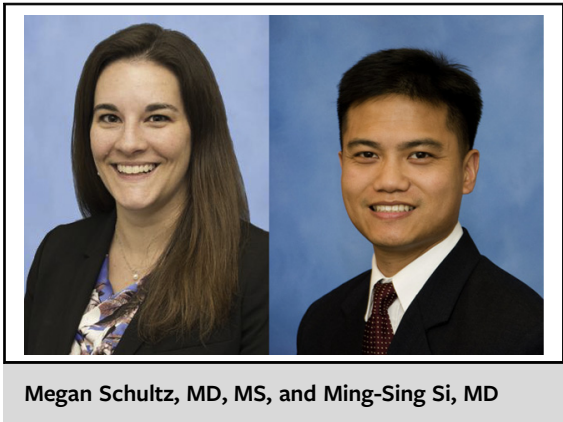

CENTRAL MESSAGE

Aortic root replacement in the reoperative setting can be performed safely in select patients.

well-matched pairs for analysis. The redo group had longer cardiopulmonary bypass and ischemic times. The groups had similar rates of operative mortality, length of stay, and postoperative complications; survival was similar at 1 and 5 years. Second, the authors performed a subgroup analysis within the redo sternotomy group. Patients undergoing first-time ARR via redo sternotomy $(n=229)$ were compared with those undergoing redo ARR $(n=69)$. Propensity matching provided 66 well-matched pairs. In this subgroup analysis, the authors found no difference between groups in any of the analyzed outcomes. Midterm survival was again similar.

The authors note that their outcomes represent those of 3 surgeons at their large-volume center. They have indeed honed their technique extensively, as described in the operative methods. However, across the country, the vast majority of centers perform fewer than 5 ARRs per year. ${ }^{1}$ With the inverse relationship between site volume and survival well established, it is reasonable to question whether these results would be reproduced in an analysis of all redo ARRs across the country.

In addition, patients who were not offered ARR are not captured in this study. As seen in Table E3 of their manuscript, within the redo sternotomy subgroup, patients who underwent reoperative ARR were younger, had fewer comorbidities, and underwent fewer concomitant procedures. Herein may lie significant selection bias if those offered reoperative ARR represent a healthier cohort. It would be of interest whether differences between groups emerge with further subgroup analyses, stratifying by various patient factors. 
Overall, the authors have presented data that address a gap in the literature. All other variables being equal, redo ARR is not riskier than first-time ARR in the postoperative and midterm follow-up periods. However, thoughtful patient selection and meticulous surgical technique may still be the best defense against poor outcomes. Long-term results of these patients with ARR in the reoperative setting are of interest.

\section{References}

1. Stamou SC, Williams ML, Gunn TM, Hagberg RC, Lobdell KW, Kouchoukos NT. Aortic root surgery in the United States: a report from the
Society of Thoracic Surgeons database. J Thorac Cardiovasc Surg. 2015; 149:116-22.e4.

2. Esaki J, Leshnower BG, Binongo JN, Lasanajak Y, McPherson L, Thourani VH, et al. Reoperative aortic root replacement: outcome in a contemporary series. $J$ Thorac Cardiovasc Surg. 2017;154:800-8.e3.

3. El-Hamamsy I, Ibrahim M, Stevens LM, Witzke H, Clark L, Yacoub MH. Early and long-term results of reoperative total aortic root replacement with reimplantation of the coronary arteries. J Thorac Cardiovasc Surg. 2011;142: 1473-7.

4. Jassar AS, Desai ND, Kobrin D, Pochettino A, Vallabhajosyula P, Milewski RK, et al. Outcomes of aortic root replacement after previous aortic root replacement: the "true" redo root. Ann Thorac Surg. 2015;99:1601-8; discussion 1608-9.

5. Brown JA, Serna-Gallegos D, Kilic A, Longo S, Chu D, Navid F, et al. Outcomes of reoperative aortic root surgery. J Thorac Cardiovasc Surg. XXX, 2021 [Epub ahead of print]. 